\title{
Contribuição da polinização entomófila para a produção de frutos de aceroleira ${ }^{1}$
}

\author{
José Eduardo Martins de Oliveira ${ }^{2}$, Daniel Nicodemo ${ }^{2}$, Favízia Freitas de Oliveira ${ }^{3}$
}

\begin{abstract}
Contribution of entomophilous pollination to fruit production of West Indian cherry plants

The production of West Indian cherry may increase considerably when its flowers are visited by bees. This study aimed to determine the dependence degree of the West Indian cherry Olivier cultivar, concerning the entomophilous pollination, as well as discovering its potential pollinators, by studying its floral characteristics and the behavior of visiting insects. The most common insects were: Centris (Centris) varia (43.9\%), Centris (Centris) decolorata (17.4\%), Centris (Centris) flavifrons (15.6\%), Epicharis (Epicharana) flava (7.6\%), Centris (Centris) nitens (5.9\%), Centris (Hemisiella) tarsata (4.9\%), Tetragonisca angustula (2.5\%) and Trigona spinipes (2.3\%). It was observed that bees from the Centris and Epicharis genera collected oil, while the T. angustula bees collected pollen and the T. spinipes bees cut the flowers. Fructification was higher when the flowers were open to pollination ( $27 \%$ of fruit production), followed by manual cross pollination (11\%) and restricted pollination (1\%). No fruits were obtained through self-pollination. The Olivier cultivar was highly dependent on entomophilous pollination and the Centris and E. flava bees can perform this service efficiently.
\end{abstract}

KEY-WORDS: Malpighia emarginata DC. Malpighiaceae; fructification; pollination.

\section{INTRODUÇÃO}

Originária da América Central, a aceroleira (Malpighia emarginata DC. Malpighiaceae), também conhecida como cerejeira-das-Antilhas, é uma planta rústica e de porte arbustivo, conhecida mundialmente pelo alto teor de ácido ascórbico (vitamina C) dos seus frutos (Costa \& Andrade 2003). No Brasil, esse fruto é bastante apreciado, sendo que o País ocupa, atualmente, o primeiro lugar na produção e exportação de acerola, em razão de diversos fatores, dentre

\section{RESUMO}

A produção de acerola pode aumentar consideravelmente, quando suas flores são visitadas por abelhas. Este estudo objetivou determinar o grau de dependência da aceroleira cultivar Olivier, em relação à polinização entomófila, bem como conhecer seus polinizadores potenciais, por meio de análise das características florais e do comportamento da entomofauna visitante. Os insetos mais frequentes foram: Centris (Centris) varia (43,9\%), Centris (Centris) decolorata (17,4\%), Centris (Centris) flavifrons (15,6\%), Epicharis (Epicharana) flava (7,6\%), Centris (Centris) nitens (5,9\%), Centris (Hemisiella) tarsata (4,9\%), Tetragonisca angustula (2,5\%) e Trigona spinipes (2,3\%). Foi observado que as abelhas dos gêneros Centris e Epicharis coletaram óleo, enquanto as T. angustula coletaram pólen e as $T$. spinipes cortaram as flores. A frutificação foi maior quando as flores estavam abertas à polinização ( $27 \%$ de frutos gerados), seguida de polinização manual cruzada (11\%) e polinização restrita (1 \%). Não houve formação de frutos por meio de autopolinização. A cultivar Oliver demonstrou alta dependência da polinização entomófila, sendo que abelhas Centris e E. flava podem realizar tal serviço eficientemente.

PALAVRAS-CHAVE: Malpighia emarginata DC. Malpighiaceae; frutificação; polinização.

eles a existência de condições edafoclimáticas favoráveis ao desenvolvimento dessa cultura (Costa \& Andrade 2003).

A área de cultivo de acerola, no Brasil, é superior a 11 mil hectares, com produção aproximada de 33.000 toneladas por ano, sendo o Nordeste responsável pela maior parte da produção (66 \%). O Estado de São Paulo figura como o terceiro maior produtor brasileiro, com cerca de $11 \%$ da produção nacional, destacando-se os municípios de Dracena e Junqueirópolis, sendo a polpa obtida por meio do

1. Trabalho recebido em mar./2014 e aceito para publicação em fev./2015 (http://dx.doi.org/10.1590/1983-40632015v4529199).

2. Universidade Estadual Paulista (Unesp), Câmpus de Dracena, Dracena, SP, Brasil. E-mails: j.eduardo@zootecnista.com.br, nicodemo@dracena.unesp.br.

3. Universidade Federal da Bahia (UFBA), Instituto de Biologia, Salvador, BA, Brasil.E-mail: favizia.freitas@ufba.br. 
processamento dos frutos destinada, principalmente, aos mercados asiático e europeu (Pinto et al. 2012).

Em geral, as aceroleiras produzem pequenas inflorescências na axila das folhas de ramos novos ou em esporões laterais, constituídas por três a cinco flores, que apresentam de cinco a sete sépalas, em cuja base estão localizadas um número variável de glândulas produtoras de óleo. As flores apresentam cinco pétalas de coloração variável (branca a diferentes tonalidades de rosa), dez estames e três carpelos unidos na base, formando o ovário, com três estiletes e estigmas. Os estigmas estão situados à mesma altura das anteras, ou um pouco acima, como forma de prevenir a autopolinização (Gomes et al. 2001).

A flor permanece aberta por um dia e, em parte desse período, fica receptiva à polinização. Apesar da proximidade entre anteras e estigmas, os grãos de pólen liberados pelas anteras dependem de polinizadores para que cheguem até os estigmas e fecundem a flor, visto que são pegajosos, o que dificulta a sua disseminação pelo vento ou pela ação da gravidade (Ritzinger et al. 2004).

Os polinizadores visitam as flores para a coleta de recursos utilizados como alimento e/ou material de construção de ninhos (Delaplane \& Mayer 2000). Enquanto realizam essa coleta, o pólen fica aderido ao seu corpo e, ao visitarem flores de diferentes plantas, promovem a polinização cruzada (Vilhena \& Augusto 2007).

Do ponto de vista do cultivo, dentre os diversos fatores que interferem na produtividade da aceroleira, podemos destacar a polinização, pois sabe-se que essa planta é dependente de polinização cruzada, para a produção satisfatória de frutos, podendo esse fator ser determinante para o sucesso ou fracasso de um cultivo comercial (McGregor 1976, Martins et al. 1999, Vilhena \& Augusto 2007). Em alguns casos, a ausência de polinizadores implica na necessidade de polinização artificial, para a produção de frutos (Krause et al. 2012).

O presente trabalho objetivou estudar a biologia floral e verificar o grau de dependência da aceroleira cultivar Olivier à polinização entomófila, bem como conhecer seus polinizadores potenciais, na região de Dracena (SP), considerando-se a biologia floral da cultura e identificando-se a entomofauna visitante de suas flores, tornando possível o diagnóstico de requerimento de polinizadores e estratégias ligadas à polinização que impliquem na maximização dos índices de produtividade da acerola.

\section{MATERIAL E MÉTODOS}

O trabalho foi realizado entre março de 2011 e fevereiro de 2012, em pomar com 5 ha não irrigado, em Dracena (SP) $\left(21^{\circ} 28^{\prime} 9,76^{\prime}\right.$ 'S, $51^{\circ} 35^{\prime} 13,08^{\prime \prime} \mathrm{W}$ e altitude de 396,22 m), no qual são cultivadas aceroleiras da cultivar Olivier. A pluviosidade média anual é de $1.513 \mathrm{~mm}$, a temperatura média de $25^{\circ} \mathrm{C}$ e o clima temperado úmido, com inverno seco e verão quente (Cwa), segundo classificação de Köppen.

$\mathrm{O}$ experimento foi dividido em quatro períodos, a partir de março de 2011, realizando-se as observações em cada um dos períodos. O primeiro, segundo, terceiro e quarto períodos abrangeram os meses de março a maio, junho a agosto, setembro a novembro e dezembro a fevereiro, respectivamente.

Foram observadas as épocas de floração, tendo sido considerada época de florada quando pelo menos $10 \%$ das plantas estivessem floridas, em uma parcela de $2.000 \mathrm{~m}^{2}$, localizada no centro do pomar.

Foi determinado o período de antese, estabelecido a partir de 10 botões previamente marcados de modo aleatório, os quais foram observados desde o processo de abertura da flor até que a última pétala se desprendesse ou murchasse no ramo, com observações feitas em 10 plantas localizadas na parte central do pomar, ou seja, 10 botões foram observados em cada uma das dez plantas avaliadas (Gomes et al. 2001).

O número de flores por inflorescência foi estimado pela contagem individual de flores em dez inflorescências, escolhendo-se cinco plantas ao acaso e avaliando-se dois ramos por planta (Gomes et al. 2001).

Para verificar o período no qual o estigma estava receptivo, foram avaliadas 10 flores tomadas aleatoriamente, em três plantas. Para tal, foi considerado o período a partir da antese, quando os ápices dos pistilos se deslocavam do ponto central em direção às laterais e apresentavam superfície estigmática viscosa e com brilho, até o momento em que se tornavam opacos e/ou ocorresse o arqueamento do ápice dos pistilos para o centro (Gomes et al. 2001).

Foi realizado o estudo da entomofauna visitante das flores da aceroleira avaliando-se a frequência de visitação dos insetos no período das $5 \mathrm{~h}$ às $19 \mathrm{~h}$, obtida por contagem, por meio de observação visual, em quatro dias. Foram percorridas três ruas no interior do plantio, com a permanência do observador por três minutos ao redor de cada planta, avaliando-se cinco plantas por rua, em cada hora do dia. 
Durante as observações, foi verificado o comportamento de forrageio dos insetos, quanto ao tipo de recurso coletado (néctar, pólen ou óleo), com cálculo da porcentagem de insetos da mesma espécie que efetuaram visitas, em relação ao total de visitas realizadas pelos insetos de todas as espécies visitantes que efetuavam coleta do mesmo recurso floral, em cada horário de avaliação.

Para medir o tempo despendido durante as visitas às flores pelos insetos mais frequentes (coletores de óleo), foi utilizado um cronômetro manual. A duração das visitas foi registrada em seis períodos ( 8 h, 10 h, 12 h, 14 h, 16 h e 18 h), com 30 repetições, em cada período experimental (Freitas et al. 1999).

Dos insetos frequentes nas flores de acerola, observados durante a avaliação da frequência de visitação de insetos, um exemplar de cada espécie foi coletado, com o auxílio de uma rede entomológica, para identificação.

Os estudos dos tipos de polinização e a verificação do vingamento dos frutos foram realizados com base nos estudos de Alves \& Freitas (2007). Foram estabelecidos tratamentos visando a diagnosticar a importância de cada tipo de polinização. O tratamento polinização livre consistiu na verificação dos níveis de polinização de flores abertas à visitação de insetos. No período de pré-antese (Figuras 1A-C), 30 botões foram marcados e as flores deles originadas foram mantidas disponíveis à visitação entomófila.

O tratamento denominado polinização restrita foi efetuado com 30 flores emasculadas, previamente marcadas no período de pré-antese, visando-se a avaliar a importância do vento na polinização da acerola. Para isso, imediatamente após o início da antese, as flores foram emasculadas com tesoura fina (Figura 1C) e protegidas da visita de insetos por sacos de filó de nylon $\left(20 \mathrm{~cm}^{2}\right.$ e malha de $\left.3 \mathrm{~mm}^{2}\right)$.
Para a determinação dos índices de autopolinização, 30 botões florais foram devidamente marcados e ensacados, permanecendo protegidos da visita de insetos por sacos de filó de nylon $\left(20 \mathrm{~cm}^{2}\right.$ e malha de $1 \mathrm{~mm}^{2}$ ). Durante a antese, os sacos foram retirados e, em seguida, foi promovido o toque das anteras de flores da mesma planta, no estigma da flor a ser polinizada.

O tratamento polinização manual cruzada foi realizado com 30 flores, sendo o método idêntico ao utilizado no tratamento autopolinização, exceto pela origem da flor doadora de pólen, que foi de outra planta, e pela emasculação da flor polinizada, evitando-se, assim, a contaminação com pólen da mesma flor.

O vingamento dos frutos foi verificado 20 dias após a polinização, sendo que os frutos que atingiram o ponto de colheita tiveram sua massa quantificada (g) e suas sementes contadas (Lopes et al. 2001).

Para as análises estatísticas, os dados obtidos foram submetidos à análise de variância e, para as comparações múltiplas, foi utilizado o teste Tukey, a 5\%. As análises foram realizadas utilizando-se o programa estatístico SAS (1993).

\section{RESULTADOS E DISCUSSÃO}

A floração das aceroleiras da cultivar Olivier ocorreu nos meses de março, abril, outubro, novembro e dezembro de 2011, e janeiro e fevereiro de 2012. Entre os meses de maio e setembro, não houve floração. Nessa época de final de outono e inverno, o fotoperíodo menor, as temperaturas mais baixas e o menor volume de chuvas na região Sudeste implicam na interrupção da produção de flores. Tais fatores contribuem para que a planta permaneça em estágio vegetativo durante os meses nos quais as condições
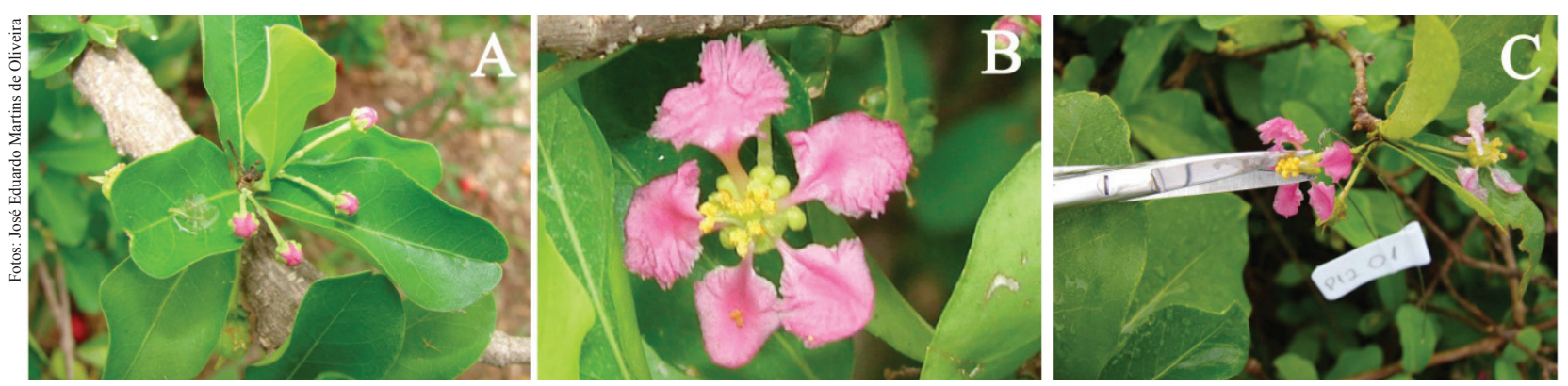

Figura 1. Flores da aceroleira Malpighia emarginata DC. Malpighiaceae, cultivar Olivier (Dracena, SP, 2012). A) botão floral em pré-antese; B) flor totalmente aberta; C) procedimento de emasculação. 
são desfavoráveis (Gomes et al. 2001, Carpentieri-Pípolo et al. 2008). Porém, quando é feita a irrigação dos pomares, nessa época, é possível a obtenção de até duas floradas. Nesse caso, um dos fatores limitantes à produção satisfatória de frutos pode ser a menor presença de agentes polinizadores, pois a menor abundância de abelhas está associada com os parâmetros ambientais também desfavoráveis a essas populações (Guedes et al. 2011).

A aceroleira floresce e frutifica várias vezes durante o ano, especialmente na primavera e verão, quando as temperaturas são mais elevadas (Ritzinger et al. 2004). De acordo com Gomes et al. (2001), podem ocorrer de seis a sete épocas de floração, que perduram, em média, de 22 a 29 dias.

Uma das grandes vantagens do cultivo dessa frutífera é o elevado número de safras por ano, sendo, geralmente, quatro, mas podendo chegar a sete safras, no caso de cultivos irrigados, ou até nove safras, em regiões tropicais (Vilhena \& Augusto 2007). As épocas de floração, durante o presente experimento, estão de acordo com os dados da literatura, tendo sido observadas sete florações, nas mesmas épocas observadas em outros estudos (Gomes et al. 2001, Ritzinger et al. 2004, Vilhena \& Augusto 2007).

Foi verificado que cada inflorescência contém, em média, quatro flores (Figura 1A). Considerando-se os três períodos de estudo nos quais houve floração, não observou-se diferença significativa $(\mathrm{p}>0,20)$, em relação ao número de flores por inflorescência (Tabela 1).

Em estudo realizado por Gomes et al. (2001), foram encontradas de 3,9 a 8,5 flores por inflorescência, nas aceroleiras estudadas, enquanto Vilhena \& Augusto (2007) observaram pequenas inflorescências constituídas de 3 a 6 flores na axila das folhas. Os números de flores verificados no presente trabalho estão dentro dos limites observados nos trabalhos citados, destacando-se a pequena amplitude, em virtude do estudo de uma única cultivar.

$O$ período de antese iniciava-se por volta das $4 \mathrm{~h}$, sendo que todas as flores estavam abertas até às $9 \mathrm{~h}$ (Figura 1B). As flores permaneciam abertas por cerca de 32 horas, até a despetala total, que acontecia das $9 \mathrm{~h}$ até às $19 \mathrm{~h}$ do dia seguinte.

A abertura das flores ocorreu às $5 \mathrm{~h} 34 \pm 62 \mathrm{~min}$. A despetala foi observada, em média, às $13 \mathrm{~h} 48 \mathrm{~min}$. do dia seguinte à abertura da flor. O tempo médio que as flores permaneceram abertas foi de $32,1 \pm 2,83 \mathrm{~h}$ (Tabela 1).

Em estudo realizado por Guedes et al. (2011), no Estado da Paraíba, o início da antese foi verificado por volta das $5 \mathrm{~h}$ da manhã, fato corroborado pelo presente trabalho e por Siqueira et al. (2011), que ainda afirmam que a antese perdura por cerca de 24 horas, baseando-se em trabalho realizado em Pernambuco. Para Gomes et al. (2001), em estudo realizado em São Paulo, a abertura floral pode ocorrer entre $5 \mathrm{~h}$ e $8 \mathrm{~h}$ e entre 14 h e 16 h. Em Minas Gerais, Vilhena et al. (2012) verificaram que a antese se iniciava a partir das $8 \mathrm{~h}$.

Quanto à coloração, observou-se que as flores novas apresentavam coloração rosa intenso e, com o passar do tempo, desbotavam até ficarem brancas, murcharem e perderem as pétalas. Esse processo durava, em média, 32,1 horas. A receptividade do estigma foi verificada por até 12,5 horas após a abertura da flor (Tabela 1). Após esse período, os estigmas não estavam mais receptivos, pois as flores começavam a entrar em senescência, murchando, perdendo o brilho e mudando a coloração das pétalas do rosa intenso para branco, com a flor perdendo a capacidade de formar o fruto.

Foram observadas oito espécies de insetos visitando as flores de acerola da cultivar Olivier, sendo todas abelhas: Centris (Centris) decolorata Lepeletier,

Tabela 1. Número médio de flores por inflorescência (NF), horário de abertura (HA) e murcha (HM) das flores, período de antese (PA) e receptividade do estigma (RE), em aceroleiras Malpighia emarginata DC. Malpighiaceae, cultivar Olivier, em quatro períodos experimentais, de março de 2011 a fevereiro de 2012 (Dracena, SP).

\begin{tabular}{lccccc}
\hline \multicolumn{1}{c}{ Período } & NF & HA & HM & PA $(\mathrm{h})$ & RE $(\mathrm{h})$ \\
\hline Março-maio & $3,9 \pm 0,9$ & $5 \mathrm{~h} 36 \pm 1,1$ & $14 \mathrm{~h} 29 \pm 2,8$ & $32,9 \pm 2,8$ & $12,6 \pm 1,3$ \\
Junho-agosto & $-*$ & - & - & - & - \\
Setembro-novembro & $3,6 \pm 1,2$ & $5 \mathrm{~h} 42 \pm 1,0$ & $14 \mathrm{~h} 40 \pm 3,4$ & $33,0 \pm 3,0$ & $12,2 \pm 0,9$ \\
Dezembro-fevereiro & $4,4 \pm 1,5$ & $5 \mathrm{~h} 23 \pm 1,0$ & $13 \mathrm{~h} 23 \pm 2,7$ & $32,0 \pm 2,7$ & $12,9 \pm 1,6$ \\
\hline Média geral & 4,0 & $5 \mathrm{~h} 34$ & $14 \mathrm{~h} 11$ & 32,1 & 12,5 \\
\hline CV $(\%)$ & 24,3 & 8,7 & 10,6 & 4,2 & 3,5 \\
\hline
\end{tabular}

* Não houve floração entre os meses de junho e agosto. 
1841 (Figuras 2A-C); Centris (Centris) flavifrons (Fabricius, 1775) (Figuras 2D-I); Centris (Centris) nitens Lepeletier, 1841 (Figura 2J); Centris (Centris) varia (Erichson, 1848)(Figura 2K); Centris (Hemisiella) tarsata Smith, 1874; Epicharis (Epicharana) flava Friese, 1900 (Figura 2L); Tetragonisca angustula
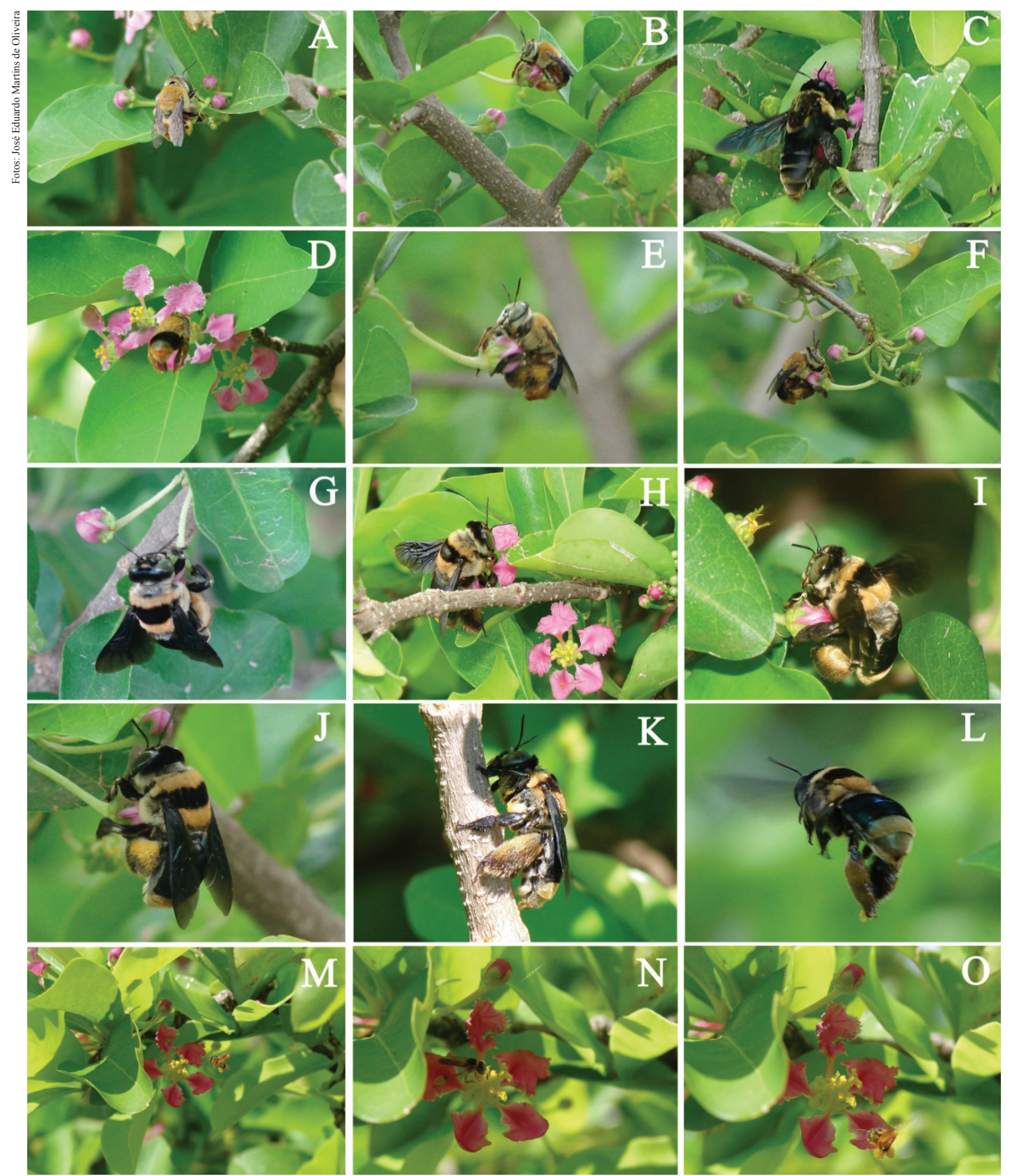

Figura 2. Abelhas visitantes florais da aceroleira Malpighia emarginata DC. Malpighiaceae, cultivar Olivier (Dracena, SP, 2012). A-C: Centris (Centris) decolorata Lepeletier; D-I: Centris (Centris) flavifrons (Fabricius); J: Centris (Centris) nitens Lepeletier, 1841; K: Centris (Centris) varia (Erichson, 1848); L: Epicharis (Epicharana) flava Friese, 1900; M-O: 16-18Tetragonisca angustula (Latreille, 1811). 
(Latreille, 1811) (Figuras 2M-O); e Trigona spinipes (Fabricius, 1793).

A espécie mais frequente nas flores de acerola foi a Centris (C.) varia, que realizou $43,9 \%$ das visitas observadas, seguida de $C$. $(C$.) decolorata $(17,4 \%)$, C. (C.) flavifrons $(15,6 \%)$, E. (E.) flava $(7,6 \%)$, C. (C.) nitens $(5,9 \%), C .(H$.$) tarsata$ (4,9\%), T. angustula (2,5\%) e T. spinipes $(2,3 \%)$ (Figura 3). Todas as abelhas observadas dos gêneros Centris Fabricius, 1804 (Figuras 2A-B, 2E-G, 2I-J) e Epicharis Klug, 1807 coletavam óleo. Abelhas Apis mellifera africanizadas não foram observadas visitando as flores da cultura da aceroleira.

Durante as visitas, observou-se que a parte ventral do corpo das abelhas ficava impregnada com pólen de acerola, o qual era disperso em outras flores visitadas pelas abelhas, no mesmo pomar. Isso era possível pela forma de pouso da abelha na flor, abraçando a mesma por cima, para raspar os elaióforos com as pernas anteriores pela borda superior da flor, tendo sido esse comportamento observado tanto em flores abertas (Figuras 2D e 2H) quanto em botões florais (Figuras 2A-B, 2E-G, 2I-J). Algumas vezes, as abelhas pousavam no tronco das árvores para se limparem (Figura 2K), antes de alçarem voo (Figura 2L).

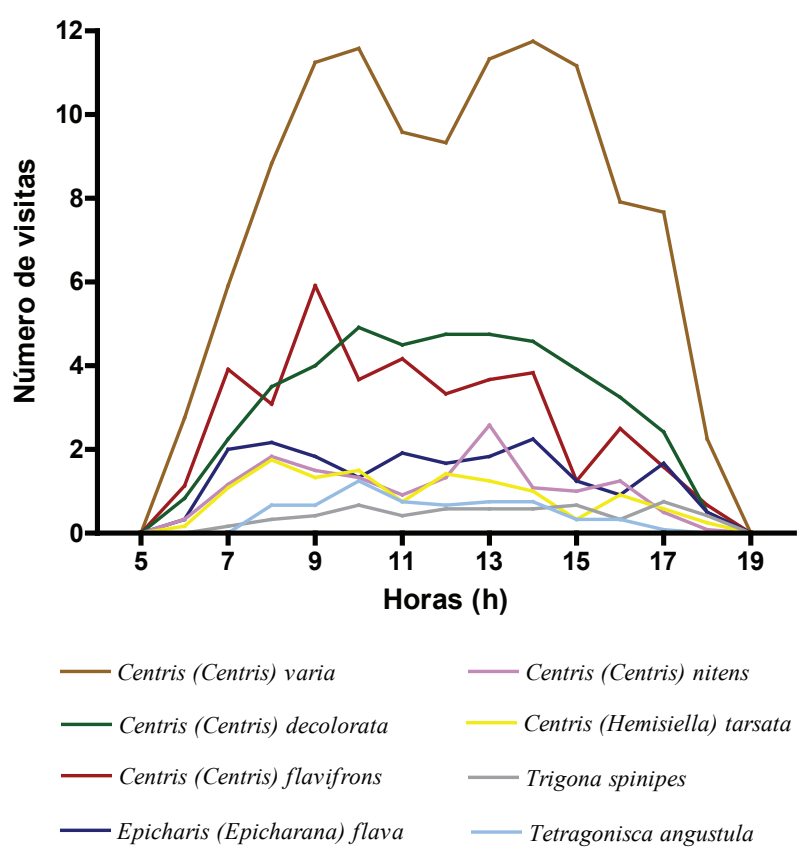

Figura 3. Frequência de visitação dos insetos mais abundantes nas flores de 15 plantas de aceroleira Malpighia emarginata DC. Malpighiaceae, cultivar Olivier, entre março de 2011 e fevereiro de 2012 (Dracena, SP).
Ao longo das observações de comportamento de visita de insetos às flores de acerola realizadas no presente trabalho, não foi verificada a coleta de pólen por abelhas dos gêneros Epicharis e Centris. Entretanto, em estudo sobre a introdução de ninhos-armadilha para nidificação de abelhas Centris (Heterocentris) analis (Fabricius) em pomares de acerola, realizado por Oliveira \& Schlindwein (2009), foi verificado que as abelhas $C$. analis coletaram preferencialmente pólen das flores de acerola, indicando seu alto potencial como polinizador para essa cultura.

Em estudo realizado por Vilhena \& Augusto (2007), em Minas Gerais, foi observada diversidade muito maior de insetos (23 espécies), a maioria do gênero Centris, algumas delas igualmente coletadas no presente estudo, como as espécies Centris $(C$.) flavifrons, C. (C.) nitens, C. (C.) varia, C. (H.) tarsata e E. (E.) flava, as quais foram classificadas como muito frequentes, pelos autores supracitados.

As abelhas Tetragonisca angustula visitaram as flores para coletar pólen, verificando-se, durante as visitas, que as corbículas ficavam carregadas de pólen de acerola (Figuras 2M-O), enquanto as Trigona spinipes apresentaram comportamento aparentemente prejudicial à cultura, pois cortavam as flores, as quais, após algumas visitas dessas abelhas, caíam. É provável que esse comportamento das abelhas tenha impedido, assim, o desenvolvimento e frutificação das flores visitadas. Estudos sugerem que essa abelha, comumente conhecida como irapuá ou arapuá, pode, eventualmente, agir como inseto-praga, prejudicando diferentes culturas (Siqueira et al. 2010).

No Brasil, abelhas dos gêneros Epicharis e Centris têm sido consideradas, por diferentes autores, como as principais polinizadoras da cultura da acerola (Freitas et al. 1999, Alves \& Freitas 2006, Oliveira \& Schlindwein 2009, Magalhães \& Freitas 2013). As flores da aceroleira produzem dois tipos principais de atrativos aos insetos visitantes: óleo e pólen, sendo o néctar um recurso escasso nas flores dessa planta. As espécies de abelhas Centridini apresentaram muita eficiência na coleta de recursos florais, visitando muitas flores por planta, ao longo do dia. Essas abelhas coletam principalmente óleos, nas flores da aceroleira, para alimentarem suas crias e impermeabilizarem seus ninhos (Vilhena \& Augusto 2007, Siqueira et al. 2011).

O período de maior visitação de abelhas às flores ocorreu entre dezembro e fevereiro, o que está 
de acordo com o ciclo de vida das abelhas solitárias observadas, as quais nascem em períodos mais quentes (Fonseca et al. 2012). Quando emergem, as abelhas saem dos ninhos e voam para coletar alimento, visando à sua própria manutenção e ao provimento de alimento para o desenvolvimento de crias (Aguiar \& Gaglianone 2003, Santos 2004).

O comportamento característico de forrageio das abelhas dos gêneros Epicharis e Centris foi verificado durante as visitas, havendo sobrevoo nas flores, para reconhecimento inicial, seguido de pouso nas mesmas, para a raspagem das glândulas produtoras de óleo (elaióforos), que ficam na parte de baixo das flores, utilizando, nessa tarefa, estruturas especializadas, localizadas nos basitarsos das pernas anteriores. Durante esse movimento, as abelhas encostavam e raspavam a porção ventral de seu corpo contra as anteras, ficando, assim, com a região ventral do corpo coberta de pólen. Ao voarem de uma flor para outra, encostavam seu corpo no estigma das diferentes flores, fazendo, dessa maneira, o transporte dos grãos de pólen entre as flores de plantas diferentes.

Entre algumas visitas, quando muito impregnadas de pólen, as abelhas coletoras de óleo realizavam um voo estacionário, para a retirada do excesso desse material de seu corpo, esfregando as pernas anteriores em sua porção ventral e passando os grãos de pólen para as pernas posteriores, até chegarem às escopas (na tíbia posterior), onde eram acumulados e, em seguida, descartados.

As abelhas jataí ( $T$. angustula) apresentaram comportamento bastante diferente, ficando em sobrevoo por um tempo, escolhendo a flor que desejavam pousar e pousando delicadamente em diferentes locais da planta (às vezes nas pétalas, às vezes nas anteras e até na parte de baixo da flor). Elas andavam pela flor e, em seguida, coletavam o pólen. Assim, pelo seu pequeno tamanho e comportamento sobre as flores, é provável que tenham atuado como meros visitantes florais coletores de pólen (pilhadores), mas não como polinizadores das flores da aceroleira.

A espécie E. (E.) flava teve o maior tempo médio de permanência na flor, para coleta de óleo (em torno de 1,5 s), não diferindo estatisticamente, porém, diferindo das espécies $C$. $(C$.) decolorata e $C$. $(C$.) nitens, que permaneceram nas flores por tempo médio de coleta de 1,3 s cada (Tabela 2).

A espécie $C$. (H.) tarsata foi a que permaneceu por menor tempo nas flores, para a coleta de recursos (em média $0,6 \mathrm{~s}$ ), porém, não diferiu estatisticamente das espécies $C$. (C.) varia (tempo médio de $0,8 \mathrm{~s}$ ) e C. (C.) flavifrons $(1,0 \mathrm{~s})$.

As taxas de frutificação variaram dependendo do tipo de polinização e entre os períodos avaliados. $\mathrm{O}$ tratamento de polinização livre foi o que obteve maiores índices de frutificação, com média de 26,7 \% (Tabela 3). Essa taxa foi alcançada em razão de os insetos poderem visitar livremente as flores, transportando pólen entre elas. Entre dezembro e fevereiro, os índices de frutificação chegaram a $38 \%$. Contudo, os índices de frutificação da acerola podem chegar a 53 \% (Martins et al. 1999), indicando que a abundân-

Tabela 2. Tempo de visita (em segundos) de insetos coletores de óleo a flores de aceroleira Malpighia emarginata DC. Malpighiaceae, cultivar Olivier, nos quatro períodos experimentais estudados (Dracena, SP, 2011/2012).

\begin{tabular}{lc}
\hline \multicolumn{1}{c}{ Abelhas } & Tempo de visita (s) \\
\hline E. (Epicharana) flava & $1,5 \pm 0,3 \mathrm{a}^{1}$ \\
C. (Centris) flavifrons & $1,0 \pm 0,2 \mathrm{bc}$ \\
C. (Centris) varia & $0,8 \pm 0,2 \mathrm{c}$ \\
C. (Centris) decolorata & $1,3 \pm 0,2 \mathrm{ab}$ \\
C. (Hemisiella) tarsata & $0,6 \pm 0,3 \mathrm{c}$ \\
C. (Centris) nitens & $1,3 \pm 0,2 \mathrm{ab}$ \\
\hline CV $(\%)$ & 34,1 \\
\hline
\end{tabular}

${ }^{1}$ Médias seguidas por letras iguais não diferem estatisticamente entre si $(\mathrm{p}>0,05)$, pelo teste Tukey.

Tabela 3. Taxa de frutificação (\%) para quatro tratamentos de polinização realizados em aceroleira Malpighia emarginata DC. Malpighiaceae, cultivar Olivier, em quatro períodos experimentais, de março de 2011 a fevereiro de 2012 (Dracena, SP).

\begin{tabular}{lccccc}
\hline \multirow{2}{*}{ Período } & \multicolumn{2}{c}{ Tipo de polinização } & \multirow{2}{*}{ Média } \\
\cline { 2 - 5 } & Livre & Restrita & Auto & Manual & 8,7 \\
Março-maio & 20,0 & 3,0 & - & 11,7 & - \\
Junho-agosto & $-*$ & - & - & - & 7,1 \\
Setembro-novembro & 21,7 & - & - & 6,7 & 13,3 \\
Dezembro-fevereiro & 38,3 & - & - & 15,0 & $9,7 \pm 1,9$ \\
\hline Média & $26,7 \pm 5,8$ & 1,0 & - & $11,1 \pm 2,4$ & \\
\hline * Não houve floração entre os meses de junho e agosto. & &
\end{tabular}


cia de agentes polinizadores na área estudada pode não ter sido suficiente para maximizar os índices de frutificação.

O tratamento polinização manual cruzada teve taxa de formação de frutos de $11,1 \%$, quando o pólen era carregado manualmente da flor de uma planta para a flor de outra planta. No tratamento polinização restrita, a taxa de frutificação foi de $1 \%$ apenas, pois as plantas foram vedadas e não recebiam os grãos de pólen carregados pelos insetos, uma vez que eles eram impedidos de chegarem até as flores. No tratamento autopolinização, não houve formação de frutos, o que pode atestar a alta dependência da aceroleira à visita de abelhas, para o desenvolvimento de frutos.

O serviço de polinização realizado por abelhas é especializado, sendo que os baixos valores de frutificação a partir de polinização manual, quando comparados aos resultados mais expressivos com polinização livre, reforçam essa ideia. Estudos realizados no Havaí, onde foi introduzida a cultura da acerola, mostraram que a produção de frutos foi aquém do potencial das plantas, mesmo com a introdução de colmeias de Apis mellifera, com o objetivo de realização da polinização da cultura. Assim, concluiu-se que a ausência de abelhas do gênero Centris, naquela ilha, impossibilitava maiores rendimentos das safras de acerola (Raw 1979).

Considerando-se que a cultura da acerola não dispõe de todos os recursos florais necessários ao desenvolvimento das abelhas, é importante que as áreas que circundam os pomares de acerola apresentem uma gama de plantas interessantes para a coleta de néctar e pólen, pelas abelhas, além de locais adequados para a nidificação desses insetos (De Marco Júnior \& Coelho 2004, Vilhena et al. 2012).

No primeiro período, os frutos mais pesados foram obtidos a partir do tratamento polinização manual cruzada $(4,6 \mathrm{~g})$. Com a polinização livre e restrita, foram obtidos frutos com peso médio de 3,9 g. Não houve diferença estatística entre os três tratamentos (Tabela 4).

Entre setembro e novembro, e de dezembro a fevereiro, os frutos obtidos a partir de flores abertas à visitação de insetos foram mais pesados $(\mathrm{p}<0,05)$ que frutos oriundos de flores polinizadas manualmente. Nesses períodos, não houve vingamento dos frutos com polinização restrita e autopolinização. Além do tipo de polinização e das condições de cultivo, a cultivar pode influenciar significativamente no peso do fruto de acerola, que pode variar em 2,3-10,0 g (Simão 1971, Freire et al. 2006). Durante o experimento, em todas as acerolas coletadas, foram encontradas três sementes.

A avaliação da presença de polinizadores em pomares de acerola é fundamental para a obtenção de boas safras. Em estudo sobre a produção de acerola com introdução de ninhos-armadilha, no Estado do Ceará, verificou-se aumento de $186 \%$ na produção de frutos, com $1.798 \mathrm{~kg} \mathrm{ha}^{-1}$ a mais de frutos em áreas nas quais os ninhos foram introduzidos, em comparação a áreas sem a introdução desses ninhos (Magalhães \& Freitas 2013).

Para a obtenção de uma boa produção de acerola, faz-se necessário o bom uso e manejo do solo, para que sejam preservados os locais de nidificação e ninhos já estabelecidos dos polinizadores potenciais, visto que, com exceção da espécie C. (Hemisiella) tarsata, todas as demais espécies polinizadoras potenciais da aceroleira nidificam no solo (Coville et al. 1983, Raw 1984, Gottsberger et al. 1988, Vinson \& Frankie 1988, Silva et al. 2001, Aguiar \& Gaglianone 2003, Aguiar \& Garófalo 2004, Aguiar et al. 2005, Gaglianone 2005, Buschini \& Wolff 2006, Rego et al. 2006, Mendes \& Rego 2007).

Tabela 4. Massa dos frutos (g) de acerola (Malpighia emarginata D.C. Malpighiaceae, cultivar Olivier), nos quatro períodos experimentais, de março de 2011 a fevereiro de 2012 (Dracena, SP).

\begin{tabular}{lccccc}
\hline \multicolumn{1}{c}{ Período } & \multicolumn{5}{c}{ Tipo de polinização } \\
\cline { 2 - 5 } & Livre $^{1}$ & Restrita & Auto & Manual $^{1}$ & \multirow{2}{*}{ Média } \\
\hline Março-maio & $3,9 \pm 0,8$ & $3,9 \pm 0,3$ & - & $4,6 \pm 0,7$ & 4,1 \\
Junho-agosto & $-*$ & - & - & - & - \\
Setembro-novembro & $5,2 \pm 0,4 \mathrm{a}$ & - & - & $3,1 \pm 0,7 \mathrm{~b}$ & 4,2 \\
Dezembro-fevereiro & $5,4 \pm 0,3 \mathrm{a}$ & - & - & $3,6 \pm 0,6 \mathrm{~b}$ & 4,6 \\
\hline Média & $4,8 \pm 0,4$ & 3,9 & - & $3,8 \pm 0,6$ & 4,3 \\
\hline
\end{tabular}




\section{CONCLUSÕES}

1. O grande período de receptividade do estigma das flores (12,5 horas) da aceroleira, com antese iniciando-se por volta das 5 h 34, constitui-se em excelente estratégia da planta, permitindo que os visitantes florais polinizadores em potencial tenham mais tempo de visitação a suas flores, uma vez que os estigmas são receptivos durante todo o período de atividade das abelhas.

2. As abelhas $C$. (C.) varia, C. (C.) decolorata, C. (C.) flavifrons, E. (E.) flava, C. (C.) nitens e $C$. $(H$.$) tarsata visitaram as flores da aceroleira$ e promoveram a polinização cruzada. É provável que a espécie Tetragonisca angustula, pelo seu pequeno tamanho e comportamento sobre as flores, tenha atuado apenas como coletora de pólen, não realizando, porém, a polinização. As abelhas Trigona spinipes danificaram as flores que visitaram e tal ação pode ter impedido o desenvolvimento de frutos.

3. A formação de frutos de acerola ocorreu quando houve polinização cruzada promovida pelas abelhas, sendo o vento pouco eficiente, enquanto agente polinizador. Não houve formação de frutos por meio de autopolinização, fato que caracteriza a cultura como altamente dependente das abelhas que efetuam a polinização.

\section{AGRADECIMENTOS}

À Fundação de Amparo à Pesquisa do Estado de São Paulo - FAPESP (processo no 10/19959-8).

\section{REFERÊNCIAS}

AGUIAR, A. J. C.; GARÓFALO, C. A.; ALMEIDA, G. F. Trap-nesting bees (Hymenoptera, Apoidea) in areas of dry semideciduous forest and Caatinga, Bahia, Brazil. Revista Brasileira de Zoologia, Curitiba, v. 22, n. 4, p. 1030-1038, 2005.

AGUIAR, C. M. L.; GAGLIANONE, M. C. Nesting biology of Centris (Centris) aenea Lepeletier (Hymenoptera, Apidae, Centridini). Revista Brasileira de Zoologia, Curitiba, v. 20, n. 4, p. 601-606, 2003.

AGUIAR, C. L. M.; GARÓFALO, C. A. Nesting biology of Centris (Hemisiella) tarsata Smith (Hymenoptera, Apidae, Centridini). Revista Brasileira de Zoologia, Curitiba, v. 21, n. 3, p. 477-486, 2004.
ALVES, J. E.; FREITAS, B. M. Requerimentos de polinização da goiabeira. Ciência Rural, Santa Maria, v. 37, n. 5, p. 1281-1286, 2007.

BUSCHINI, M. L.; WOLFF, L. L. Nesting biology of Centris (Hemisiella) tarsata Smith in southern Brazil (Hymenoptera, Apidae, Centridini). Brazilian Journal of Biology, São Carlos, v. 66, n. 4, p. 1091-1101, 2006.

CARPENTIERI-PÍPOLO, V. et al. Frutificação e desenvolvimento de frutos de aceroleira no norte do Paraná. Ciência Rural, Santa Maria, v. 38, n. 7, p. 18711876, 2008.

COSTA, F. A.; ANDRADE, W. D. C. A cultura da acerola no Brasil e no Pará: aspectos estruturais de produção e mercado. Belém: ADS/Amazônia, 2003.

COVILLE, R. E.; FRANKIE, G. W.; VINSON, S. B. Nests of Centris segregate (Hymenoptera: Anthoporidae) with a review of the nesting habits of the genus. Journal of the Kansas Entomological Society, Washington, DC, v. 56, n. 2, p. 109-122, 1983.

DELAPLANE, K. S.; MAYER, D. F. Crop pollination by bees. New York: CABI Publishing, 2000.

DE MARCO JUNIOR, P.; COELHO, F. M. Services performed by the ecosystem: forest remnants influence agricultural cultures' pollination and production. Biodiversity and Conservation, Madrid, v. 13, n. 7, p. 12451255, 2004.

FONSECA, V. L. I. et al. Polinizadores no Brasil: contribuição e perspectivas para a biodiversidade, uso sustentável, conservação e serviços ambientais. São Paulo: Edusp, 2012.

FREIRE, J. L. O. et al. Características físicas de frutos de acerola cultivada em pomares de diferentes microrregiões do Estado da Paraíba. Agropecuária Técnica, Areia, v. 27, n. 2, p. 105-110, 2006.

FREITAS, B. M. et al. Pollination requirements of West Indian-cherry (Malpighia emarginata) and its putative pollinators, Centris bees, in NE Brazil. Journal of Agricultural Science, Toronto, v. 133, n. 3, p. 303-311, 1999.

GAGLIANONE, M. C. Nesting biology, seasonality, and flower hosts of Epicharis nigrita (Friese, 1900) (Hymenoptera: Apidae: Centridini), with a comparative analysis for the genus. Studies on Neotropical Fauna and Environment, London, v. 40, n. 3, p. 191-200, 2005.

GOMES, J. E. et al. Morfologia floral e biologia reprodutiva de genótipos de aceroleira. Scientia Agricola, Piracicaba, v. 58, n. 3, p. 519-523, 2001.

GOTTSBERGER, G.; CAMARGO, J. M. F.; SILLBERBAUER-GOTTSBERGER, I. A bee pollinated 
tropical community: the beach dune vegetation of Ilha de São Luís, Maranhão, Brazil. Botanische Jahrbuecher fuer Systematik, Stuttgart, v. 109, n. 4, p. 469-500, 1988.

GUEDES, R. S. et al. Déficit de polinização da aceroleira no período seco no semiárido paraibano. Revista Brasileira de Fruticultura, Jaboticabal, v. 33, n. 2, p. 465-471, 2011.

KRAUSE, W. et al. Produtividade e qualidade de frutos de cultivares de maracujazeiro-amarelo com ou sem polinização artificial. Pesquisa Agropecuária Brasileira, Brasília, DF, v. 47, n. 12, p. 1737-1742, 2012.

LOPES, R. et al. Repetibilidade de características do fruto de aceroleira. Pesquisa Agropecuária Brasileira, Brasília, DF, v. 36, n. 3, p. 507-513, 2001.

MAGALHÃES, C. B.; FREITAS, B. M. Introducing nests of the oil-collecting bee Centris analis (Hymenoptera: Apidae: Centridini) for pollination of acerola (Malpighia emarginata) increases yield. Apidologie, Paris, v. 44, n. 2, p. 234-239, 2013.

MARTINS, C. G. M.; LORENZON, M. C. A.; BAPTISTA, J. L. Eficiência de tipos de polinização em acerola. Revista Caatinga, Mossoró, v. 12, n. 1, p. 55-59, 1999.

McGREGOR, S. E. Insect pollination of cultivated crop plants. Washington, DC: Agricultural Research Service, 1976.

MENDES, F. N.; REGO, M. M. C. Nidificação de Centris (Hemisiella) tarsata Smith (Hymenoptera, Apidae, Centridini) em ninhos-armadilha no nordeste do Maranhão, Brasil. Revista Brasileira de Entomologia, Curitiba, v. 51, n. 3, p. 382-388, 2007.

OLIVEIRA, R.; SCHLINDWEIN, C. Searching for a manageable pollinator for acerola orchards: the solitary oil-collecting bee Centris analis (Hymenoptera: Apidae: Centridini). Journal of Economic Entomology, Riverside, v. 102, n. 1, p. 265-273, 2009.

PINTO, L. B. et al. Aspectos históricos e organizacionais da agricultura familiar no desenvolvimento da região Nova Alta Paulista. Revista Brasileira de Gestão e Desenvolvimento Regional, Taubaté, v. 8, n. 2, p. 130150, 2012.

RAW, A. Centris dirrhoda (Anthophoridae), the bee visiting West Indian cherry flowers (Malpighia punicifolia). Revista de Biologia Tropical, San José, v. 27, n. 2, p. 203 205, 1979.

RAW, A. The nesting biology of nine species of Jamaican bees. Revista Brasileira de Entomologia, Curitiba, v. 28, n. 4, p. 497-506, 1984.

REGO, M. M. C. et al. Aspectos da biologia de nidificação de Centris flavifrons (Friese) (Hymenoptera: Apidae, Centridini), um dos principais polinizadores do murici
(Byrsonima crassifolia L. Kunth, Malpighiaceae), no Maranhão. Neotropical Entomology, Londrina, v. 35, n. 5, p. 579-587, 2006.

RITZINGER, R.; SILVA, L. C. V.; ALVES, M. G. V. Polinização da aceroleira: acerola em foco. Cruz das Almas: Embrapa, 2004.

SANTOS, I. A. dos. Biologia de nidificação de Anthodioctes megachiloides Holmberd (Anthidiini, Megachilidae, Apoidea). Revista Brasileira de Zoologia, Curitiba, v. 21, n. 4, p. 739-744, 2004.

SAS INSTITUTE. Statistical analysis systems: user's guide. Version 6. 4. ed. Cary: SAS Institute, 1993.

SILVA, F. O.; VIANA, B. F.; NEVES, E. L. Biologia e arquitetura de ninhos de Centris (Hemisiella) tarsata Smith (Hymenoptera: Apidae: Centridini). Neotropical Entomology, Londrina, v. 30, n. 4, p. 541-545, 2001.

SIMÃO, S. Manual de fruticultura. São Paulo: Ceres, 1971.

SIQUEIRA, K. M. et al. Estudo comparativo da polinização em variedades de aceroleiras (Malpighia emarginata DC, Malpighiaceae). Revista Caatinga, Mossoró, v. 24, n. 2, p. 18-25, 2011.

SIQUEIRA, T. M. T. et al. Influência do dano da abelhairapuá em flores de mirtileiro sobre a frutificação efetiva e as frutas produzidas. Revista Brasileira de Fruticultura, Jaboticabal, v. 32, n. 1, p. 303-307, 2010.

VILHENA, A. M. G. F.; AUGUSTO, S. C. Polinizadores da aceroleira Malpighia emarginata DC. (Malpighiaceae) em área de Cerrado no Triângulo Mineiro. Bioscience Journal, Uberlândia, v. 23, supl., p. 14-23, 2007.

VILHENA, A. M. G. F. et al. Acerola pollinators in the Savanna of Central Brazil: temporal variations in oil-collecting bee richness and a mutualistic network. Apidologie, Paris, v. 43, n. 1, p. 51-62, 2012.

VINSON, S. B.; FRANKIE, G. W. A comparative study of the ground nests of Centris flavifrons and Centris aethiocesta (Hymenoptera: Anthophoridae). Entomologia Experimentalis et Applicata, Amsterdam, v. 49, n. 1-2, p. 181-187, 1988. 